\title{
Variation in Root System Architecture among the Founder Parents of Two 8-way MAGIC Wheat Populations for Selection in Breeding
}

\author{
Shree R. Pariyar ${ }^{1, * \mathbb{D}}$, Kerstin A. Nagel ${ }^{1, * \mathbb{D}}$, Jonas Lentz ${ }^{1} \mathbb{D}$, Anna Galinski ${ }^{1} \mathbb{D}$, Jens Wilhelm ${ }^{1}$, Alexander Putz ${ }^{1}$, \\ Sascha Adels ${ }^{1}$, Kathrin Heinz ${ }^{1}$, Claus Frohberg ${ }^{2}$ and Michelle Watt ${ }^{1,3}$ (D) \\ 1 Institute of Bio- and Geosciences, Plant Sciences (IBG-2), Forschungszentrum Jülich GmbH, \\ 52425 Jülich, Germany; j.lentz@fz-juelich.de (J.L.); a.galinski@fz-juelich.de (A.G.); \\ j.wilhelm@fz-juelich.de (J.W.); a.putz@fz-juelich.de (A.P.); s.adels@fz-juelich.de (S.A.); \\ kathrin.heinz@gmx.de (K.H.); watt.m@unimelb.edu.au (M.W.) \\ 2 BASF Innovation Center Gent, BASF Belgium Coordination Center CommV, Technologiepark-Zwijnaarde 101, \\ 9052 Gent, Belgium; claus.frohberg@basf.com \\ 3 School of BioSciences, University of Melbourne, Parkville, VIC 3010, Australia \\ * Correspondence: s.pariyar@fz-juelich.de (S.R.P.); k.nagel@fz-juelich.de (K.A.N.)
}

Citation: Pariyar, S.R.; Nagel, K.A.; Lentz, J.; Galinski, A.; Wilhelm, J.; Putz, A.; Adels, S.; Heinz, K.; Frohberg, C.; Watt, M. Variation in Root System Architecture among the Founder Parents of Two 8-way MAGIC Wheat Populations for Selection in Breeding. Agronomy 2021 11, 2452. https://doi.org/10.3390/ agronomy 11122452

Academic Editor: Tristan Edward Coram

Received: 12 October 2021 Accepted: 22 November 2021 Published: 30 November 2021

Publisher's Note: MDPI stays neutral with regard to jurisdictional claims in published maps and institutional affiliations.

Copyright: (C) 2021 by the authors Licensee MDPI, Basel, Switzerland. This article is an open access article distributed under the terms and conditions of the Creative Commons Attribution (CC BY) license (https:// creativecommons.org/licenses/by/ $4.0 /)$

\begin{abstract}
Root system architecture (RSA) is a target for breeding crops with effective nutrient and water use. Breeding can use populations designed to map quantitative trait loci (QTL). Here we noninvasively phenotype roots and leaves of the 16 foundation parents of two multi-parent advanced generation inter-cross (MAGIC) populations, covering diversity in spring (CSIRO MAGIC) and winter (NIAB MAGIC) wheats. RSA components varied after 16 days in the upgraded, paper-based imaging platform, GrowScreen-PaGe: lateral root length 2.2 fold; total root length, 1.9 fold; and seminal root angle 1.2 fold. RSA components total and lateral root length had the highest root heritabilities $\left(\mathrm{H}^{2}\right)\left(\mathrm{H}^{2}=0.4\right.$ for CSIRO and NIAB parents) and good repeatability $(\mathrm{r}=0.7)$ in the GrowScreen-PaGe. These can be combined with leaf length $\left(\mathrm{H}^{2}=0.8 \mathrm{CSIRO} ; 0.7 \mathrm{NIAB}\right)$ and number $\left(\mathrm{H}^{2}=0.6\right.$ CSIRO; 0.7 NIAB) to identify root and shoot QTL to breed for wheats with vigorous RSA and shoot growth at establishment, a critical phase for crop productivity. Time resolved phenotyping of MAGIC wheats also revealed parents to cross in future for growth rate traits (fastest: Robigus-NIAB and AC Barrie-CSIRO; slowest Rialto-NIAB and G204 Xiaoyan54-CSIRO) and root: shoot allocation traits (fast growers grew roots, notably laterals, quicker than leaves, compared to slow growers).
\end{abstract}

Keywords: wheat; MAGIC parents; root traits; variation; non-invasive; phenotyping; breeding; GrowScreen-PaGe; National Institute of Agricultural Botany (NIAB); Commonwealth Scientific and Industrial Research (CSIRO)

\section{Introduction}

Bread wheat (Triticum aestivum L.) is a staple food crop for the world, providing $19 \%$ of the calories and $20 \%$ of the protein in human diets [1,2]. Wheat is an allohexaploid with three closely related but independently maintained genomes combined by multiple hybridizations among three progenitor species. The first hybridization occurred between the wild diploid wheat T. urartu $(\mathrm{AA}, 2 \mathrm{n}=14)$ and an unknown species containing the $\mathrm{B}$ genome (BB, $2 \mathrm{n}=14$, most probably Aegilops speltoides), resulting in the tetraploid ancestor of modern wheat species, wild emmer wheat T. turgidum ssp. dicoccoides, AABB, $2 \mathrm{n}=28$ ). Wild emmer further hybridized with goat grass $A$. tauschii (DD, $2 \mathrm{n}=14$ ) to produce today's modern bread wheat [2-5]. As a consequence of hybridization of three genomes, the entire bread wheat genome is exceptionally large compared to the other staple cereals maize and rice, and only recently a fully annotated reference genome has become available [6].

Genetic improvement of wheat relies on diversity in the phenotypes and genotypes of parents and populations, and heritable and repeatable quantitative trait loci (QTL). 
Bi-parental mapping population possess allelic diversity of two parents, whereas multiparent advanced generation inter-cross (MAGIC) mapping populations have higher allelic diversity, higher levels of recombination, and the genomes form a fine-scale mosaic of several parents [7-9]. Combined with high density molecular markers and sequence information, MAGIC populations serve as a new generation of mapping populations for QTL discovery. Several populations are available for wheat [10-14]. The eight CSIRO MAGIC parents are spring wheats from Australia, Asia, and North America, selected based on diverse geographical distribution and agronomical performance [10,12]. The CSIRO MAGIC parents were previously used to identify QTLs linked to rhizosheath size (using bound soil and root hair length as phenotypes) [15], above ground coleoptile length and seedling leaf growth [16], spikelet formation, grain dormancy [17,18], and canopy architecture [19]. The NIAB MAGIC parents include eight European winter wheats from the United Kingdom and France (Figure 1), and were selected based on yield, breadmaking quality and disease resistance [8]. The NIAB MAGIC wheat population was successfully used to identify QTLs linked to leaf senescence and plant height [20], presence or absence of awns [8], resistance to Septoria tritici [21], and leaf and glume blotch [22]. More generally among wheat genotypes, previous studies have shown higher distribution of roots in topsoil for both winter and spring wheats at early stages of plant development while deeper root/rooting depth was recorded with winter wheat at later stages of plant growth $[23,24]$. The deeper rooting of winter wheat in the field may have resulted from genotype $\mathrm{X}$ environment (accumulated temperature) as winter wheat is sown in autumn and develops slowly during the cold periods.

Improving root traits for breeding is a promising strategy to speed up genetic gain for plant performance [25]. Root system architecture (RSA) is the spatial distribution of roots in a particular environment and is determined by genetic and environmental factors [26,27]. RSA is associated with yield of wheat in the field, with deeper and longer root systems correlated with greater yields where deep water is available [28]. Underlying components of RSA are root number, elongation rate and root angle [27]; these measures can result in root lengths with depth through the soil [29-31], including in the early vegetative phase in different field conditions [32]. In wheat and other small grain cereals, root systems are composed of root types, differentiated based on their tissue of origin. A seminal root system originates from the seed embryo, and a nodal root system originates from leaf nodes, each with axile roots and lateral roots. The seminal roots are the first to emerge from the seed upon germination, and their elongation rate and angle support axial transport of water and nutrients to the shoot until at least 3 to 4 leaves, when nodal axile roots emerge if conditions are favorable [33]. Lateral roots begin to make up most of the root length of the entire root system after two leaves across a range of species including wheat [32,33] and can contribute to larger root systems and positive associations with yield in the field [34]. In maize lateral roots have been shown to be important for accessing water [25,26,35], at least in part because of their dominant length [36]. It is important to use a phenotyping method for roots that allows quantification of all components of RSA, including the fine lateral roots.

Phenotypes for QTL must be repeatable and heritable [37-39]. Controlled environment phenotyping is currently a preferred option to field phenotyping because of the ability to control variability and increase repeatability and heritability [38]. The phenotypes of young wheat plants such as seminal root length and total root length measured in control environments correlate well to expression in fields of those phenotypes [32,40]. Direct root phenotyping in the field is difficult mainly due to the opaque nature of soil, and for finer crop roots is restricted to coring, shovelomics and minirhizotrons, which only reveal part of root systems $[25,26,41]$. Phenotyping of large-scale mapping populations require a significant amount of time and resources. Here, we used the non-invasive, high-throughput phenotyping system 'GrowScreen-PaGe', previously applied to shoots and roots of young rapeseed, maize, barley, and wheat plants [37]. This system has several features critical to root phenotyping: precision, as it allows the complete root system to be quantified in $2 \mathrm{D}$ 
using a high-resolution camera; repeatability, because plants are grown on germination paper to control for effects of soil variability; and throughput, as the method can scale to high replicates and plant numbers and be readily established in other laboratories.

This study reports on the phenotypic variation in early root and shoot traits of the CSIRO and NIAB MAGIC wheat parents. By using GrowScreen-PaGe, we quantified the variation, heritability and repeatability of component phenotypes of RSA including seminal and lateral lengths, angles and dynamic traits such as rates of growth, extracted from images. We also determined allocation between root and shoot growth within and across the MAGIC wheat parents. The aim of the study was to identify root traits in these parents of MAGIC populations that could be selected in future pre-breeding and breeding using phenotyping or QTL-based markers.

\section{Materials and Methods}

\subsection{Plant Materials}

We analyzed two sets of eight-way MAGIC wheat founder parents: CSIRO MAGIC [10] and NIAB MAGIC [11] (Figure 1). The founder parents have diverse origins (Figure 1), pedigrees, yield, grain quality, disease resistance and growth parameters (Table S1). The NIAB parents are winter wheat cultivars from the United Kingdom (Alchemy, Brompton, Claire, Hereward, Rialto, Robigus and Xi-19), and France (Soissons) (Figure 1) [11]. The CSIRO parents are spring wheat cultivars from Australia (H5 Yitpi, C207 Baxter, Chara7 and F201 Westonia, China (G204 Xiaoyan54), Israel (Volcani), Canada (AC Barrie), USA (B207 Alsen), and Mexico (D204 Pastor) (Figure 1) [10]. The cultivar Chara7 was included to develop four-way population, however; was excluded from eight-way MAGIC wheat population. See Table S1 for all sources and/or original breeding entity for the parent seed, along with pedigrees and characteristics.

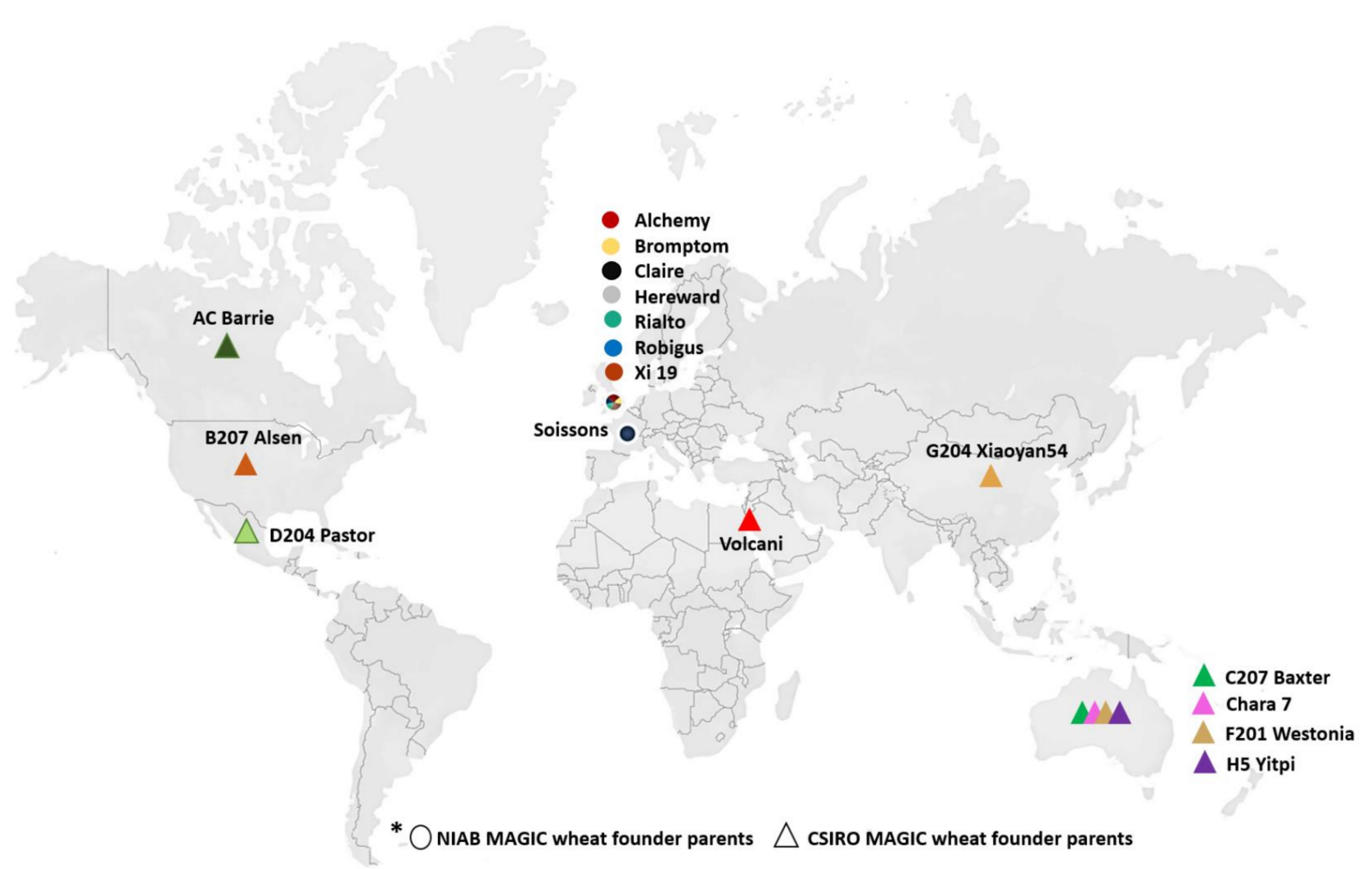

Figure 1. Geographic distribution of MAGIC wheat founder parents used in this study. NIAB MAGIC founder parents (circle symbols) originated from the UK (7) and France (1). The CSIRO MAGIC founder parents (triangle symbols) originated from Australia (4 lines) and one each from China, Israel, Canada, USA, and Mexico. The details of the origin and attributes of both set of MAGIC founder parent lines are listed in Table S1. 


\subsection{Phenotyping System}

Phenotyping was performed using the GrowScreen-PaGe phenotyping platform which is based on repeated imaging of root development on wetted germination paper. The platform used is as described in Gioia et al. (2016) with the following modifications. Wetted germination paper (smooth dark blue 194 grade paper; Ahlstrom Germany GmbH, Bärenstein, Germany) was fixed onto dark grey PVC plates (RAL 7011, Max Wirth GmbH, Germany) rather than transparent PMMA plates with transparent shirt clips (Hemdklammer 38 mm, Georg Scharf GmbH, Balingen, Germany) [37]. New opaque polypropylene containers $\left(60 \times 40 \times 42 \mathrm{~cm}^{3}\right.$, Eurobehälter, EG 64/42 HG, Auer Packaging GmbH, Amerang, Germany) replaced those used in Gioia et al. (2016) to prevent light entering through handles [37]. PVC containers were covered by a new custom-made polypropylene lid with adjustable black strip brushes in the middle that allow leaf emergence and growth (Mink GmbH \& Co. KG, Göppingen, Germany). Finally, PVC plates $\left(37.5 \times 30 \times 0.2 \mathrm{~cm}^{3}\right)$ and germination paper $\left(37 \times 25 \mathrm{~cm}^{2}\right)$ were adjusted in size to fit the new containers (see Figure S1A,B for the new set up).

\subsection{Plant Cultivation and Experimental Design}

Seeds were pre-coated with the fungicide prothioconazole $(33 \mathrm{ml} / 100 \mathrm{~kg}$ seed $)$ and then germinated in the dark in Petri dishes between two wet filter papers at $22{ }^{\circ} \mathrm{C}$ for $24 \mathrm{~h}$. The seeds were pure and multiplied from single seed descent. Seeds with the first seminal root emerged from the base of the embryo and ca. 1.5-1.7 mm length were transplanted onto the GrowScreen-PaGe germination paper with the seminal root facing downward. The seedlings were fixed to the germination paper using a transparent, self-adhesive tape (Opsite Flexifix, 7478029, Smith \& Nephew GmbH, Hamburg, Germany) (Figure 2), replacing the fold-back butterfly clips and filter paper used in Gioia et al. (2016), allowing the angle of seminal root emergence to be imaged. After fixing the germinated seed, a modified Hoagland nutrient solution [42] was sprayed evenly over the germination paper to the point of saturation with Gloria sprayers (Gloria Haus \& Gartengeräte $\mathrm{GmbH}$, Witten, Germany, EAN 400632571 7872). Up to 25 PVC plates with one germination paper and one seedling on each side (two plants per plate) were positioned vertically and $2.0 \mathrm{~cm}$ apart in the opaque containers (Figure S1B). Each container was filled with $12 \mathrm{~L}$ of the modified Hoagland nutrient solution, submerging the bottom $5 \mathrm{~cm}$ of germination papers. The nutrient solution was replaced once a week. Each experiment contained 8 replicates (plants) of each parent ( 8 plants $\times 17$ parents $=136$ plants $)$ which were arranged in a completely randomized block design. In total, three successive experimental repeats were conducted. Plants were grown in a controlled growth chamber at $22{ }^{\circ} \mathrm{C} / 18{ }^{\circ} \mathrm{C}$ (day/night) air temperature, $12 \mathrm{~h} / 12 \mathrm{~h}$ light $/$ dark, $60 \%$ relative air humidity and $\sim 150 \mu \mathrm{mol} \mathrm{m}^{-2} \mathrm{~s}^{-1}$ photosynthetically active radiation (PAR) at leaf level (Johnson Controls Systems \& Service $\mathrm{GmbH}$, Leipzig, Germany).

Plants were harvested at 16 days after transplanting (DAT) and number of leaves and length of longest leaf were measured manually. Further, roots and shoots were separated above the seed, oven-dried at $65^{\circ} \mathrm{C}$ for one week and dry weight was recorded using a balance (Mettler Toledo ${ }^{\mathrm{TM}}$, Model: XS-205DU, analytical balances, Fischer Scientific, Gießen, Germany). 


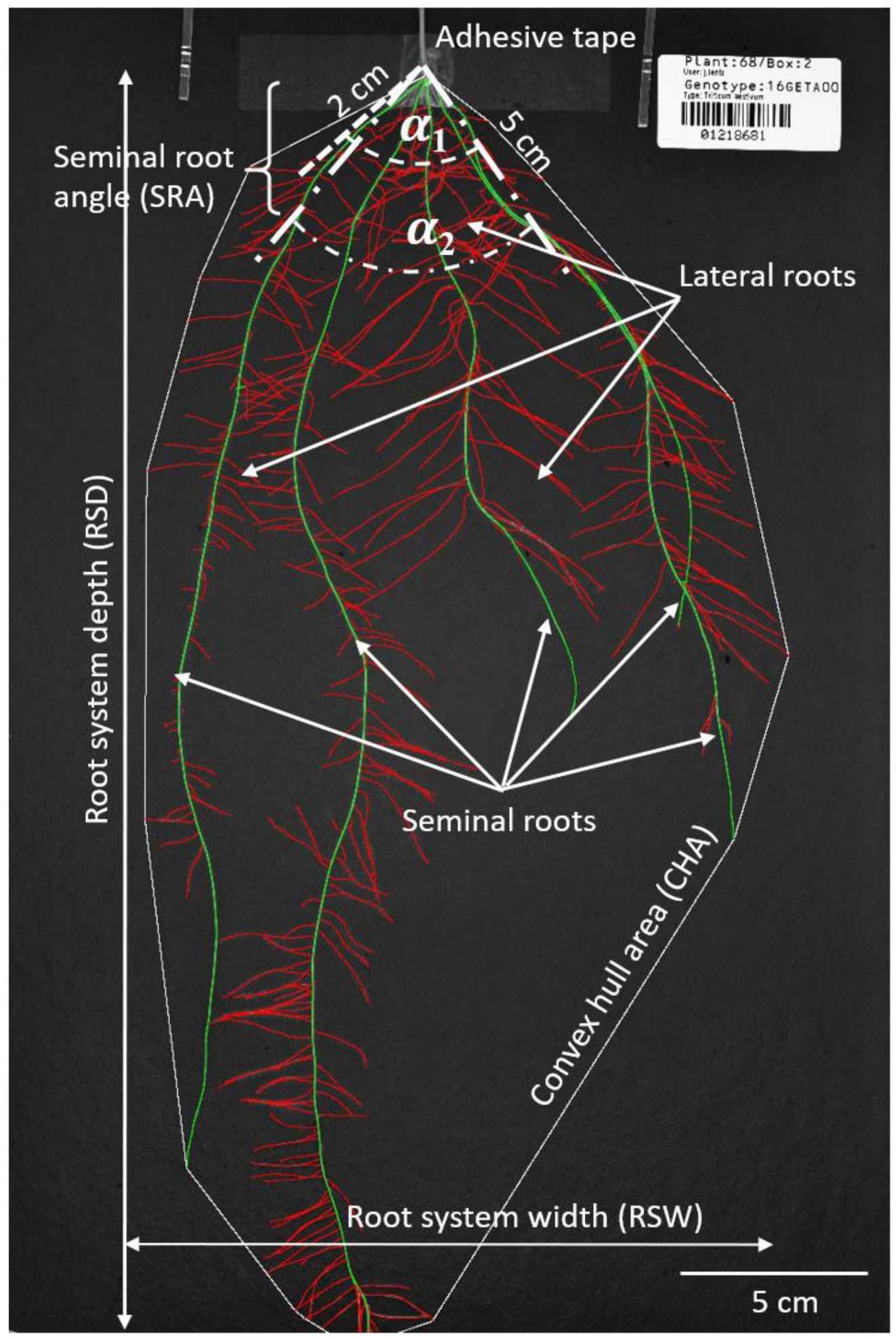

Figure 2. Typical wheat root system analyzed at 16 days after transplanting by the image processing workflow of the GrowScreen-PaGe platform. Root lengths of different root classes (seminal roots marked in green; and lateral roots marked in red) are analyzed separately. Further spatial quantifications include maximum root system depth (RSD) and width (RSW) (indicated by white vertical and horizontal lines) as well as convex hull area (CHA, the area covered by the root system indicated by the white line surrounding the root system). The seminal root angle (SRA) between the two outermost seminal roots is measured at $2 \mathrm{~cm}\left(\alpha 1-\mathrm{SRA}_{2 \mathrm{~cm}}\right)$ and $5 \mathrm{~cm}\left(\alpha 2-\mathrm{SRA}_{5 \mathrm{~cm}}\right)$ distances from the seed. 


\subsection{Image Acquisition and Analysis}

Root systems were photographed at 2,9 and 16 DAT onto the germination papers, using the mobile imaging box described in Gioia et al. (2016) with an upgraded, less manual image-processing workflow [37]. The first images could be taken 2 DAT and allowed measurement of seedling establishment on the germination paper. Thereafter, we imaged the roots every 7 days for 2 weeks. The final time point 16 DAT was determined by roots reaching the nutrient level. Three major software parts and steps were added. First is the 'Segmenter', which segments root parts from the background and labels those as developmental types based on their points of origin (seminal roots originating from seed; lateral roots originating from seminal or first order lateral roots). The second step is called 'PaintRoot', a graphical user interface to check the automatic labeling provided by the 'Segmenter' and allows manual correction of the segmentation and labeling in the mask images if required. The third step is the 'Analyzer', which processes the checked or corrected image (Figure S1D) to quantify the root phenotypes. These new software steps were used to quantify total root length (TRL), seminal root length (SRL), lateral root length (LRL), seminal root angle (SRA) between two outermost seminal roots at a distance of $2 \mathrm{~cm}$ $\left(\mathrm{SRA}_{2 \mathrm{~cm}}\right)$ and $5 \mathrm{~cm}$ from the seed $\left(\mathrm{SRA}_{5 \mathrm{~cm}}\right)$, root system depth (RSD), root system width (RSW), and convex hull area (CHA). See detailed list and definitions of all measured root and shoot growth traits in Table 1 and Figure 2.

Table 1. List of measured root and shoot traits in this study.

\begin{tabular}{llc}
\hline \multicolumn{1}{c}{ Trait } & \multicolumn{1}{c}{ Description } & Unit \\
\hline First seminal root (FSR) & Length of radicle (measured 1 day after germination) & $\mathrm{mm}$ \\
Seminal root length (SRL) & Length of all seminal roots & $\mathrm{cm}$ \\
Lateral root length (LRL) & Length of all roots branched from seminal roots & $\mathrm{cm}$ \\
Total root length (TRL) & Total sum of seminal and lateral root length & $\mathrm{cm}$ \\
Root system depth (RSD) & Maximal vertical depth of a root system & $\mathrm{cm}$ \\
Root system width (RSW) & Maximal horizontal distribution of a root system & $\mathrm{cm}$ \\
Convex hull area (CHA) & Area of the convex hull that encompasses the root system & $\mathrm{cm}{ }^{2}$ \\
Seminal root angle (SRA) & Angle between the outermost left and right seminal roots & $\circ$ \\
Leaf length (LeafL) & measured at 2 or 5 cm distance from seed respectively & $\mathrm{cm}$ \\
Number of leaves (LeafNo) & Length between the seed and tip of the longest leaf & - \\
Root dry weight (RDWeight) & Number of leaves (without cotyledons) & $\mathrm{g}$ \\
Shoot dry weight (SDWeight) & Root dry weight & $\mathrm{g}$ \\
Root mass ratio (RMR) & Shoot dry weight & $\mathrm{g} / \mathrm{g}$ \\
Shoot mass ratio (SMR) & Dry mass of root divided by the total dry mass of entire plant & $\mathrm{g} / \mathrm{g}$ \\
\hline
\end{tabular}

\subsection{Statistical Analysis}

The data were analyzed with a one-way analysis of variance (ANOVA), noting significant differences between means at a level of $P \leq 0.05$ using SigmaPlot 13.0 (Sigma Stat, Systat Software Inc., Richmond, CA, USA). The coefficient of variation (CV) was calculated as the ((SD / mean) * 100), where SD = standard deviation. The CV indicates the extent of variation of a phenotype relative to its mean. Broad-sense heritability $\left(\mathrm{H}^{2}\right)$ was calculated in SAS (SAS 9.4) according to $[43,44]$ :

$$
\mathrm{H}^{2}=\sigma_{\mathrm{g}}^{2} /\left(\sigma_{\mathrm{g}}^{2}+\sigma_{\mathrm{e}}^{2} / \mathrm{n}\right),
$$

where $\sigma_{g}^{2}=$ genotypic variance; $\sigma^{2}=$ environmental variance, and $\mathrm{n}=$ number of replicates.

Repeatability ( $\mathrm{r}$ ) across three successive experiments was calculated as the variance among group means (group-level variance $\mathrm{V}_{\mathrm{G}}$ ) over the sum of group-level and data-level (residual) variance $V_{R}$ followed by confidence interval at 1000 bootstrap [45]. Pearson correlations and regressions between traits were evaluated by generating a correlation matrix. Repeatability, correlations and regression were analyzed in R3.5 [46]. 


\section{Results}

\subsection{Variation in Root Lengths and Biomass Was Observed in Both Sets of MAGIC Parents}

The parents of both MAGIC wheat populations had substantial variability for root length and dry biomass phenotypes at the final time point (16 DAT) of the study (Figure 3). Within the NIAB parents, Robigus, Soissions and Alchemy had the longest median total root length while Rialto and Hereward had the shortest median total root length (Figure 3A). Within the CSIRO parents, AC Barrie, B207 Alsen, and D204 Pastor had the longest median total root length while G204 Xiaoyan54 and C207 Baxter had the shortest (Figure 3A). The median value of root dry biomass ranged from 17 to $27 \mathrm{mg}$ and 18 to $33 \mathrm{mg}$ for the NIAB and CSIRO parents, respectively (Figure 3D). On average, the CSIRO parents had 1.3 times greater total root length than the NIAB parents. This was due to slightly longer (1.1 times) seminal roots and relatively longer (1.3 times) lateral roots. CSIRO founder parents also had greater root as well as shoot biomass (1.2 times, Figure 3B-C) than the NIAB parents (Figure 3D, Tables S1 and S2). Additionally, we found $41 \%$ longer leaf length and $40 \%$ more shoot dry weight with CSIRO parents compared to NIAB (Tables S2 and S3).

\subsection{Slow and Fast Growing Founder Parents Differed Most through Elongation Rates of Lateral Roots}

We dissected the temporal dynamics and root types for the two parents per population that contrasted most for total root length (Figure 4). By 16 DAT, within NIAB founder parents, the slowest growing Rialto had 1.5-fold less total root length than the fastest growing Robigus (Figure 4A-C); within CSIRO parents, the slowest growing G204 Xiaoyan54 had 1.9-fold less total root length than AC Barrie (Figure 4E-G). Lateral root length variation was most notable at driving these contrasts, differing 1.7 times between the slowest and fastest parents of the NIAB parents, and 2.2 times between the two extreme CSIRO parents at 16 DAT. Further, analysis of root growth dynamics over time showed that rates of lateral root growth were higher in fastest growing parents compared to slow growing parents in both NIAB and CSIRO MAGIC parents (Figure 4D,H). The growth rate of lateral roots was 2.6 times higher in Robigus compared to Rialto, while lateral root growth rate in AC Barrie was 3.4 times higher compared to G204 Xiaoyan54. However, no significant differences were recorded for root system depth between fastest and slowest growing parents although the fast-growing parents grew slightly deeper (Figure 4I-J). At 16 DAT, most of the roots had reached the bottom of the germination paper, restricting extraction of reliable data at this imaging time point. 

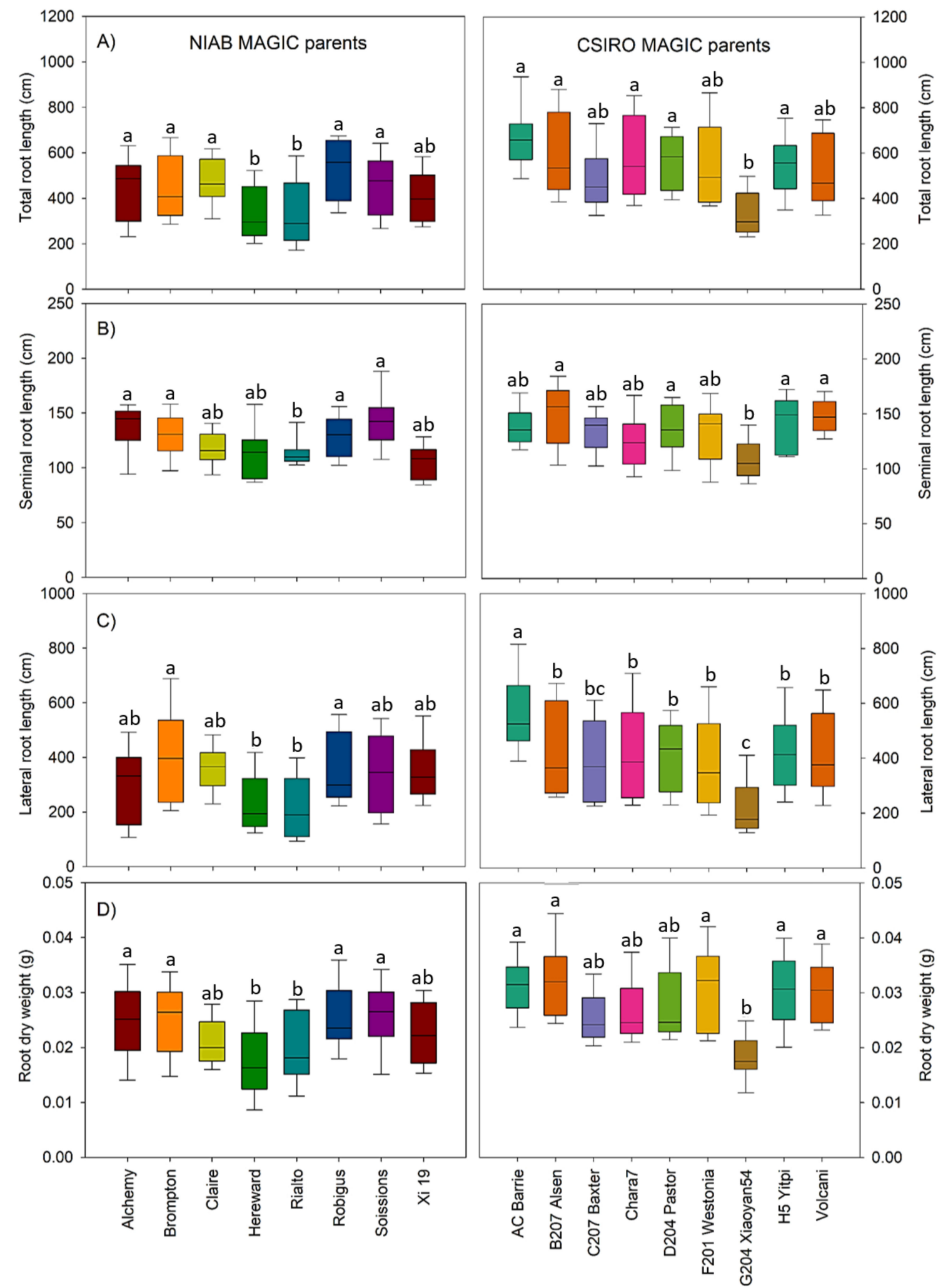

Figure 3. Phenotyping variation in root traits measured at 16 days after transplanting. NIAB MAGIC wheat founder lines (left panel) and CSIRO MAGIC wheat founder parents (right panel). (A) Total root length, (B) Seminal root length, (C) Lateral root length, and (D) root dry weight. The boxes indicate the 25th and 75th percentile of the distribution, the 'whiskers' the 10th and 90th percentile and the lines in the middle of the box the median value. Letters indicate significant differences between parents $(p<0.05)$ according to one way ANOVA analysis, a $>$ b > c, $n=24$ (pooled data from 3 successive experiments). 

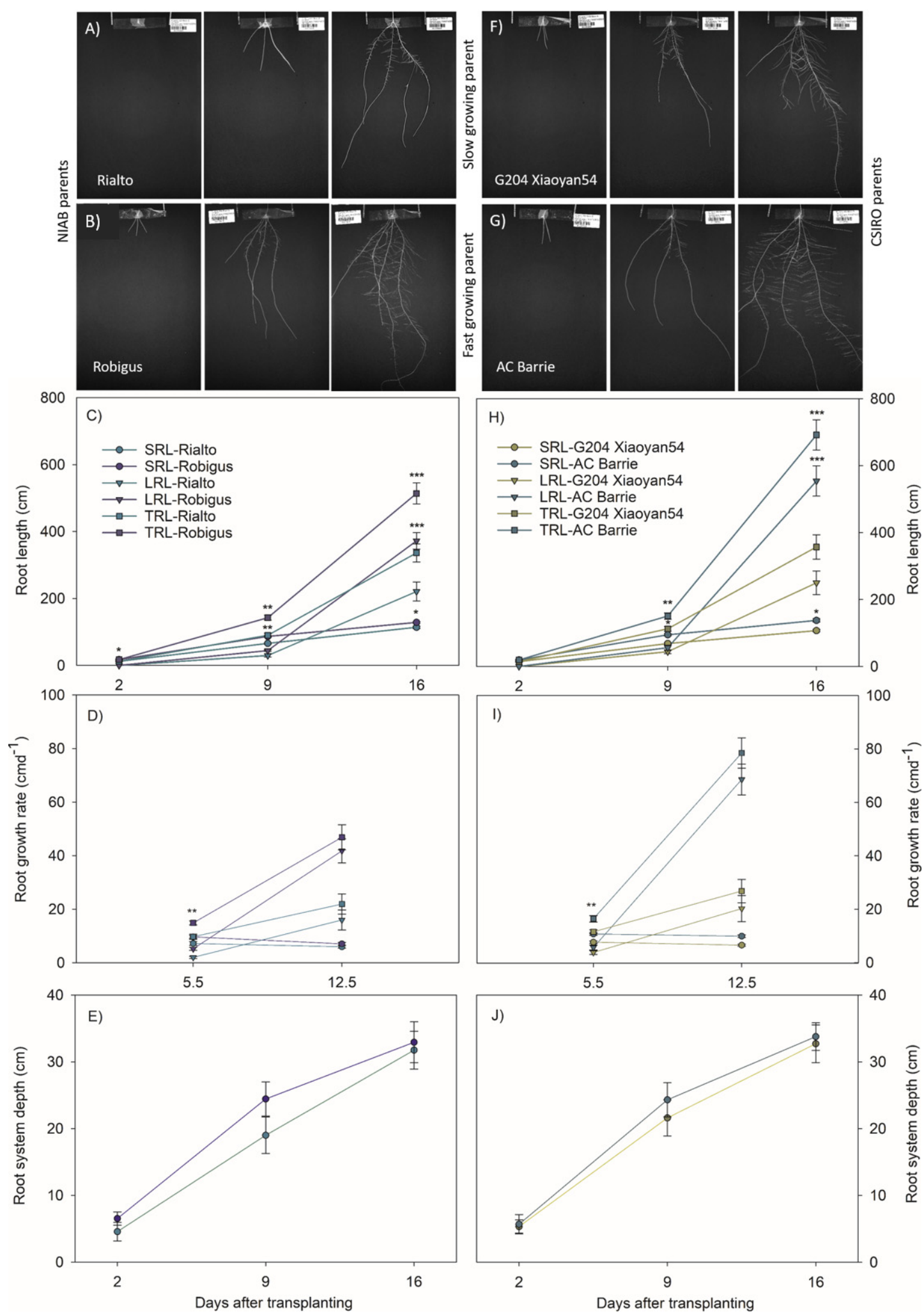

Figure 4. Root growth dynamic of selected slow and fast-growing MAGIC wheat founder parents over time. The slow growing lines Rialto (NIAB) and G204 Xiaoyan54 (CSIRO) and fast-growing lines Robigus (NIAB) and AC Barrie (CSIRO) were selected based on total root length differences at 16 DAT. Typical original root images of slow $(\mathbf{A}, \mathbf{F})$ and fast-growing lines $(\mathbf{B}, \mathrm{G})$ at 2, 9 and 16 days after transplanting. Seminal root length (SRL), lateral root length (LRL), and total root length (TRL) $(\mathbf{C}, \mathbf{H})$, dynamic of root growth $(\mathbf{D}, \mathbf{I})$ and root system depth $(\mathbf{E}, \mathbf{J})$ were analyzed. Line with asterisk indicate significant differences at ${ }^{*} p<0.05,{ }^{* *} p<0.01,{ }^{* *} p<0.001$, and $n=24$ according to one way ANOVA analysis. 


\subsection{Phenotypic Variation for Seminal Root Angles Was Observed Only across CSIRO MAGIC Parents}

We analyzed the root angle between the two widest seminal roots at $\mathrm{SRA}_{2 \mathrm{~cm}}$ and $\mathrm{SRA}_{5 \mathrm{~cm}}$, and found significant variation only across CSIRO MAGIC parents (Figure 5, Figure S2), although $\mathrm{SRA}_{2 \mathrm{~cm}}$ and $\mathrm{SRA}_{5 \mathrm{~cm}}$ increased and were correlated positively through time (Figure S2, Tables S2 and S3). No significant differences for seminal root angle were found within NIAB parents (Figure $5 \mathrm{~A}, \mathrm{~B}$ ). NIAB parents had a slightly narrower $\mathrm{SRA}_{2 \mathrm{~cm}}$ compared to that of CSIRO over time (Figure $S 2 A-C$ ), but $S R A_{5 \mathrm{~cm}}$ was narrower in CSIRO parents than in NIAB (Figure 5A,B). For CSIRO MAGIC parents, wide $\mathrm{SRA}_{5 \mathrm{~cm}}$ correlated to the total length and rate of total root length growth of the root system (Figure 5A-C). However, this pattern of wider root angle linked to fast growing parent (AC Barrie) and narrow angle to slow growing parent (G204 Xiaoyan54) was not found for NIAB parents (Figure 5A,B, Figure S2A-C).

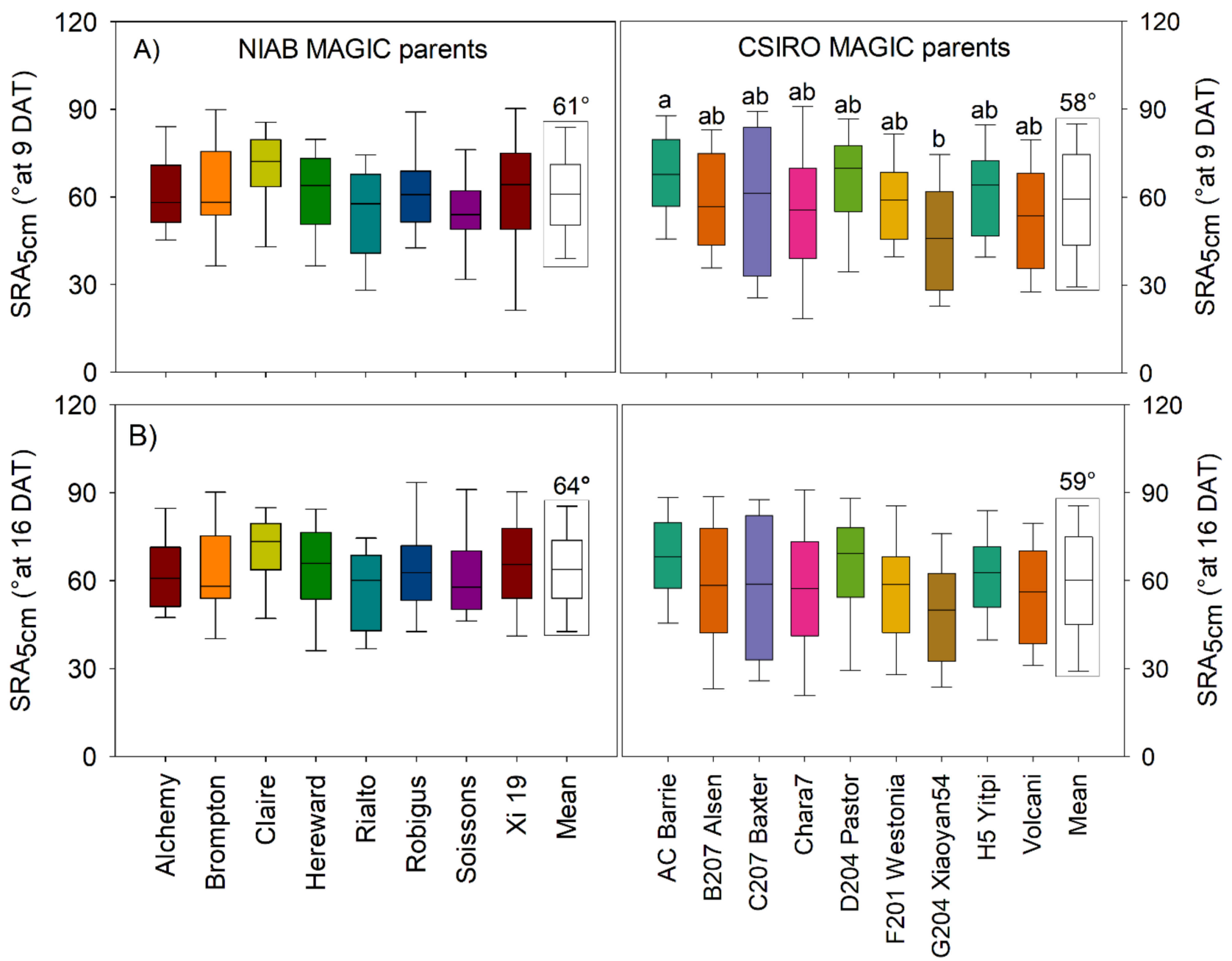

Figure 5. Variation for root angle measured between the two outmost seminal roots at a distance of $5 \mathrm{~cm}\left(\mathrm{SRA}_{5 \mathrm{~cm}}\right)$ over time. (A) $\mathrm{SRA}_{5 \mathrm{~cm}}$ at 9 days after transplanting (DAT), and (B) $\mathrm{SRA}_{5 \mathrm{~cm}}$ at 16 DAT. The boxes indicate the 25th and 75th percentile of the distribution, the 'whiskers' the 10th and 90th percentile and the lines in the middle of the box the median value. Letters indicate significant differences between parents $(p<0.05)$, according to one way ANOVA analysis, a $>\mathrm{b}, n=24$. Boxes highlighted with rectangular black line indicate mean seminal root angle (SRA) across NIAB and CSIRO wheat founder parents.

Our results suggested that variation in seminal root angles $\left(\mathrm{SRA}_{2 \mathrm{~cm}}\right.$ and $\left.\mathrm{SRA}_{5 \mathrm{~cm}}\right)$ depended on cultivar, time and position of the measurement (Figure 5, Figure S2). Note 
that at $2 \mathrm{DAT}$, the length of seminal roots was shorter than $5 \mathrm{~cm}$ and consequently no $\mathrm{SRA}_{5 \mathrm{~cm}}$ could be quantified and was measured at 9 and 16 DAT only (Tables S2 and S3).

\subsection{Traits with High Heritability, Repeatability and Correlations for Selection in Breeding}

Heritability $\left(\mathrm{H}^{2}\right)$ and repeatability $(\mathrm{r})$ ranged widely for root and shoot traits in both sets of MAGIC wheat parents (Table 2). Highest heritability which was found for NIAB was 0.67 , and 0.84 for CSIRO parents (Table 2). Both sets of parents had high heritability for leaf length and number (Table 2); moderate heritability for first seminal, lateral and total root length; and low heritability for root system depth, root system width, seminal root angle at 2 and $5 \mathrm{~cm}$ distance, and convex hull area.

Table 2. Heritability and repeatability of root and shoot traits in both sets of MAGIC wheat founder parents. Heritability was analyzed separately for both NIAB and CSIRO founder parents, while repeatability was analyzed by combining NIAB and CSIRO parents $(n=24)$. DAG = day after germination, DAT = day after transplanting, low $(\leq 0.3)$, moderate $(0.3-0.6)$ and high (>0.6).

\begin{tabular}{|c|c|c|c|}
\hline \multirow{3}{*}{ Trait } & \multicolumn{2}{|c|}{ Heritability $\left(\mathbf{H}^{2}\right)$} & Repeatability (r) \\
\hline & \multicolumn{2}{|c|}{ MAGIC Founder Parents } & \multirow{2}{*}{ MAGIC Founder Parents } \\
\hline & NIAB & CSIRO & \\
\hline First seminal root (1 DAG) & 0.43 & 0.64 & 0.36 \\
\hline Seminal root length (2 DAT) & 0.29 & 0.32 & 0.58 \\
\hline Seminal root length (9 DAT) & 0.20 & 0.44 & 0.54 \\
\hline Seminal root length (16 DAT) & 0.23 & 0.35 & 0.44 \\
\hline Lateral root length (9 DAT) & 0.40 & 0.22 & 0.34 \\
\hline Lateral root length (16 DAT) & 0.36 & 0.38 & 0.65 \\
\hline Total root length (2 DAT) & 0.29 & 0.32 & 0.58 \\
\hline Total root length (9 DAT) & 0.36 & 0.19 & 0.44 \\
\hline Total root length (16 DAT) & 0.35 & 0.40 & 0.67 \\
\hline Root system depth (2 DAT) & 0.38 & 0.07 & 0.30 \\
\hline Root system depth (9 DAT) & 0.30 & 0.19 & 0.42 \\
\hline Root system depth (16 DAT) & 0.12 & - & 0.10 \\
\hline Root system width (2 DAT) & 0.25 & 0.12 & 0.24 \\
\hline Root system width (9 DAT) & 0.24 & 0.30 & 0.34 \\
\hline Root system width (16 DAT) & 0.16 & 0.29 & 0.23 \\
\hline Seminal root angle $2 \mathrm{~cm}$ (2 DAT) & - & 0.06 & 0.23 \\
\hline Seminal root angle $2 \mathrm{~cm}$ (9 DAT) & 0.06 & 0.10 & 0.14 \\
\hline Seminal root angle $2 \mathrm{~cm}$ (16 DAT) & - & 0.22 & 0.06 \\
\hline Seminal root angle $5 \mathrm{~cm}$ (9 DAT) & 0.41 & 0.10 & 0.08 \\
\hline Seminal root angle $5 \mathrm{~cm}$ (16 DAT) & 0.30 & 0.20 & 0.21 \\
\hline Convex hull area (2 DAT) & 0.39 & 0.13 & 0.33 \\
\hline Convex hull area (9 DAT) & 0.23 & 0.24 & 0.32 \\
\hline Convex hull area (16 DAT) & 0.12 & 0.26 & 0.19 \\
\hline Leaf length (16 DAT) & 0.60 & 0.84 & 0.58 \\
\hline Leaf number (16 DAT) & 0.67 & 0.61 & 0.42 \\
\hline Root dry weight (16 DAT) & 0.25 & 0.50 & 0.34 \\
\hline Shoot dry weight (16 DAT) & 0.37 & 0.50 & 0.38 \\
\hline
\end{tabular}

Repeatability was calculated across all founding parents to establish the replication needed in the GrowScreen PaGe platform for large scale screening of progenies in future. It was highest for total root length $(r=0.67)$ and lowest $(r=0.10)$ for root system depth across MAGIC parents (Table 2). Repeatability was also low for root system width, seminal root angle and convex hull area; while moderate to high repeatabilities were recorded for seminal and lateral root length, and leaf length (Table 2).

Similarly, Pearson correlation coefficients (R) between root types and shoot phenotypes ranged widely in both sets of MAGIC parents (Figure 6A,B). At 16 DAT, high correlation was recorded between root dry weight and shoot dry weight $\left(\mathrm{R}^{2}=0.775\right.$ for NIAB and $R^{2}=0.741$ for CSIRO, Figure $\left.7 C, F\right)$ while the lowest correlations $(R=0.002-0.007$, 
Figure 6A,B) were recorded between seminal root angle and root system depth, and seminal root angle and root system width in both MAGIC sets. For NIAB parents, total root length and root dry weight $\left(\mathrm{R}^{2}=0.528\right.$, Figure $\left.7 \mathrm{~B}\right)$, was moderately correlated, and seminal and lateral root length ( $\mathrm{R}^{2}=0.22$ for NIAB, Figure $\left.7 \mathrm{~A}\right)$ had low correlations. For CSIRO parents, correlations were slightly higher than those of $\operatorname{NIAB}\left(\mathrm{R}^{2}=0.692\right.$ total root length vs. root dry weight, Figure $7 \mathrm{E}$ and $\mathrm{R}^{2}=0.620$ total root length vs. shoot dry weight, Figure $7 \mathrm{~F}$ ), except of the correlation between seminal and lateral root length $\left(R^{2}=0.10\right.$, Figure $\left.7 D\right)$, Table S4.

Although, heritability, repeatability and correlations between root and shoot traits varied over time, lengths of first seminal root, lateral root and total root lengths, and leaf number and length had the most consistent moderate to high heritability and repeatability. These traits can be targeted for selection in breeding. CV for all root and shoot phenotypes was as high as $62 \%$ across NIAB and as high as $63 \%$ for CSIRO parents (Tables S5 and S6). Lower CVs $(<40 \%)$ were recorded for root system depth and width, while higher CVs $(\geq 40 \%)$ were linked to first seminal root length, lateral root length and convex hull area of both sets of MAGIC parents.

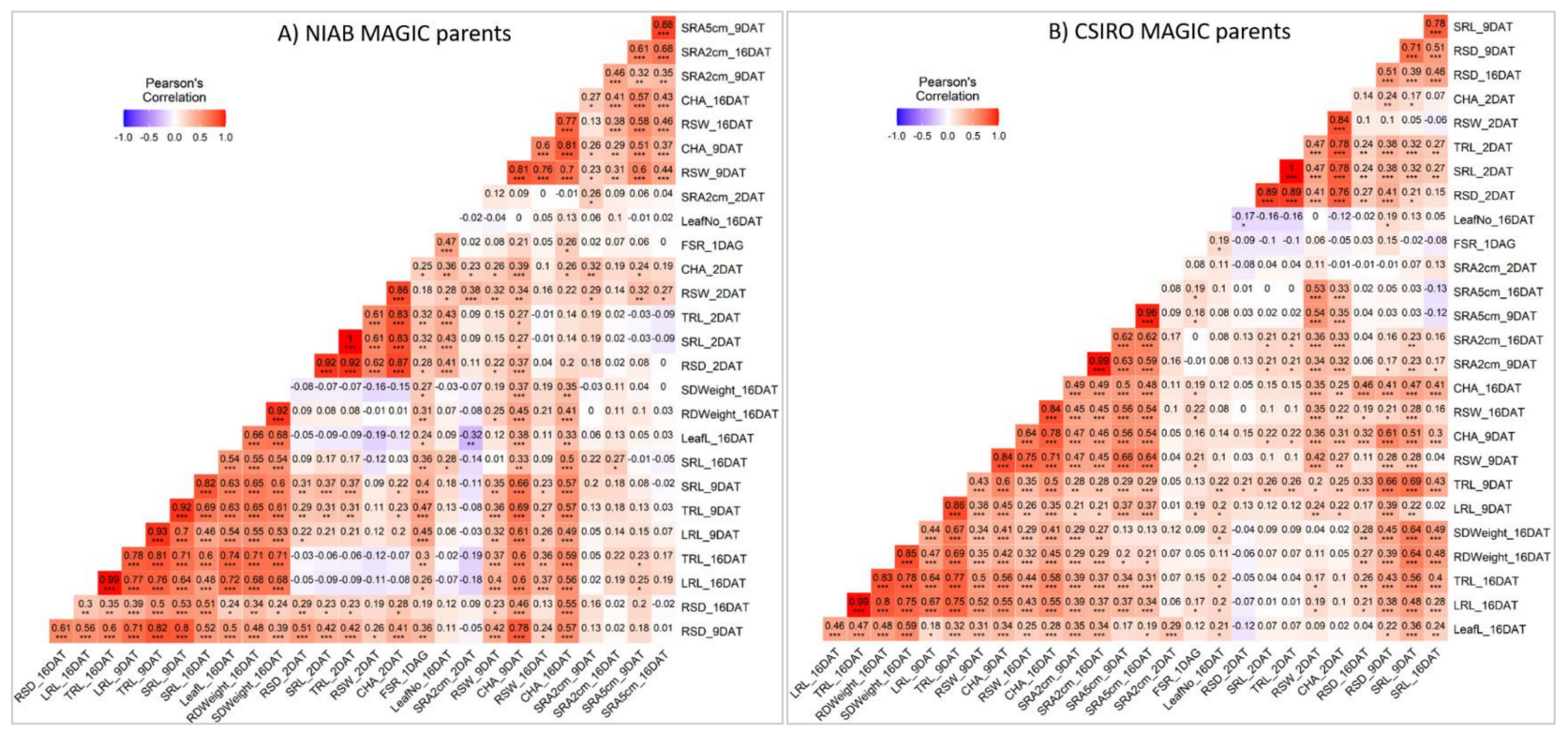

Figure 6. Pearson's correlation matrix between root and shoot traits of MAGIC wheat founder parents, (A) NIAB MAGIC wheat parents and (B) CSIRO MAGIC wheat parents. Intensity of color indicates correlation among the traits ranges from $(1$ to -1$)$ and is the fraction of the variance in the two variables that is "shared". FSR first seminal root length, SRL seminal root length, LRL lateral root length, TRL total root length, SRA seminal root angle, RSD root system depth, RSW root system width, CHA convex hull area, RDWeight root dry weight, LeafL longest leaf length, LeafNo leaf number, SDWeight shoot dry weight, DAG days after germination, DAT days after transplanting. Number with asterisk indicates significant differences at ${ }^{*} p<0.05,{ }^{* *} p<0.01,{ }^{* * *} p<0.001$ and $n=24$. 

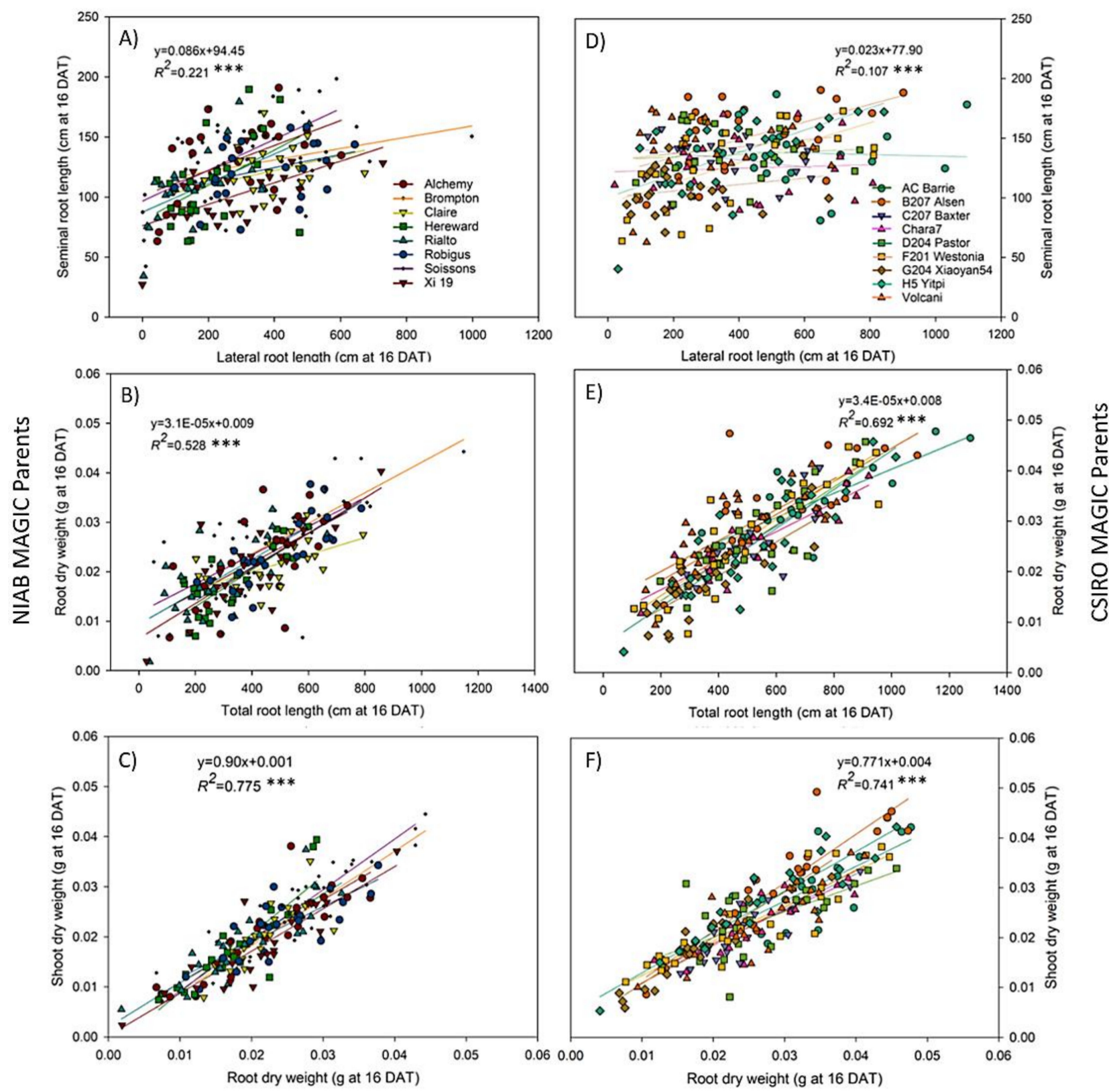

Figure 7. Relationship between traits of MAGIC wheat founder parents (NIAB (A-C), and CSIRO (D-F) at 16 days after transplanting (DAT). (A,D) correlation between seminal and lateral root length, (B,E) correlation between root dry weight and total root length, and $(\mathbf{C}, \mathbf{F})$ correlation between shoot and root dry weight. Mean of correlations across MAGIC founder parents were shown $\left(n=24,{ }^{* * *} p<0.001\right)$.

\subsection{Fast Growing Parents Allocated More Resources to the Roots during Early Stages of Plant Development}

Root and shoot biomass allocation varied between and across both sets of MAGIC parents at 16 DAT (Table 3). CSIRO parents had 1.2-fold greater root and shoot dry biomass than NIAB parents (Table 3). Fast growing parents produced more total plant biomass (Robigus produced 1.22 fold more biomass compared to Rialto, while AC Barrie produced 1.7 fold more compared to G204 Xiaoyan54) compared to slow growing parents in both sets of MAGIC parents (Tables S2 and S3). We found striking contrast for root mass ratio (RMR) and shoot mass ratio (SMR) between fast and slow growing parents in both MAGIC sets at 16 DAT. For example, RMR was higher in fast growing parents Robigus (0.52) and AC Barrie (0.53) at 16 DAT while SMR is higher for slow growing parents Rialto (0.51) and G204 Xiaoyan54 (0.50) (Table 3). This reflects that the higher proportion of resources were 
allocated to the roots during the early stages of plant development in fast growing parents while slow growing parents tend to allocate more resources into shoot development.

Table 3. Biomass allocation between root and shoot of both sets of MAGIC wheat founder parents at 16 days after transplanting, mean values are shown. Different letters indicate significant differences at $p=0.05, n=24 ; \mathrm{a}>\mathrm{b}$.

\begin{tabular}{|c|c|c|c|c|c|}
\hline MAGIC Wheat & Founder Parents & $\begin{array}{c}\text { Root Dry Weight } \\
\text { (g) }\end{array}$ & $\begin{array}{l}\text { Shoot Dry Weight } \\
\text { (g) }\end{array}$ & Root Mass Ratio & Shoot Mass Ratio \\
\hline \multirow{8}{*}{ NIAB } & Alchemy & $0.022 \mathrm{a}$ & $0.021 \mathrm{ab}$ & 0.513 & 0.487 \\
\hline & Brompton & $0.027 \mathrm{a}$ & $0.024 a$ & 0.525 & 0.475 \\
\hline & Claire & $0.021 \mathrm{ab}$ & $0.020 \mathrm{ab}$ & 0.516 & 0.484 \\
\hline & Hereward & $0.017 \mathrm{~b}$ & $0.018 \mathrm{~b}$ & 0.493 & 0.507 \\
\hline & Rialto & $0.019 b$ & $0.019 b$ & 0.492 & 0.508 \\
\hline & Robigus & $0.024 \mathrm{a}$ & $0.022 \mathrm{ab}$ & 0.516 & 0.484 \\
\hline & Soissons & $0.024 \mathrm{a}$ & $0.023 a$ & 0.511 & 0.489 \\
\hline & Xi-19 & $0.021 \mathrm{ab}$ & $0.018 b$ & 0.529 & 0.471 \\
\hline \multirow{9}{*}{ CSIRO } & AC Barrie & $0.033 a$ & $0.029 a$ & 0.529 & 0.471 \\
\hline & B207 Alsen & $0.030 \mathrm{a}$ & $0.031 \mathrm{a}$ & 0.493 & 0.507 \\
\hline & C207 Baxter & $0.024 \mathrm{ab}$ & $0.021 b$ & 0.53 & 0.47 \\
\hline & Chara7 & $0.026 \mathrm{ab}$ & $0.023 \mathrm{ab}$ & 0.533 & 0.467 \\
\hline & D204 Pastor & $0.027 \mathrm{ab}$ & $0.023 \mathrm{ab}$ & 0.526 & 0.474 \\
\hline & F201 Westonia & $0.026 \mathrm{ab}$ & $0.024 \mathrm{ab}$ & 0.524 & 0.476 \\
\hline & G204 Xiaoyan54 & $0.018 b$ & $0.018 b$ & 0.497 & 0.503 \\
\hline & H5 Yitpi & $0.026 \mathrm{ab}$ & $0.026 \mathrm{ab}$ & 0.501 & 0.499 \\
\hline & Volcani & $0.028 \mathrm{a}$ & $0.024 \mathrm{ab}$ & 0.533 & 0.467 \\
\hline
\end{tabular}

\section{Discussion}

We aimed to identify root traits in the NIAB and CSIRO MAGIC founder parents that could be selected using phenotyping or QTL-based markers in future. We revealed variation that was heritable and repeatable for component phenotypes contributing to RSA in both sets of parents using the GrowScreen-PaGe phenotyping platform. We show that measuring RSA non-invasively over time using a high throughput phenotyping platform enables the selection of key traits that could be amenable to QTL identification and breeding in future. Roots are targets for wheat breeding today and phenotypes such as rapid and long seminal roots, and long lateral roots, along with long first leaves, are good targets for direct selection in breeding for whole plant establishment. Rapid establishment confers greater ground cover, greater root system soil colonization and improved crop nutrient-use efficiencies [47]. These roots and shoot traits combined are advantageous for contemporary farming systems that do not plough the soil [48]. Selecting a single trait may not be effective. Targeting two key traits (one below and one above ground) with high heritability may serve as more reliable index for trait selection. A platform such as GrowScreen-PaGe allows co-selection of root and shoot traits, potentially speeding up introgression of traits and genetic gain within a germplasm enhancement pipeline [25].

\subsection{Key Traits for Potential Selection in Breeding}

Root phenotypes with the highest heritabilities and repeatabilities were total root length $\left(\mathrm{H}^{2}=0.40\right.$ CSIRO, $\left.0.35 \mathrm{NIAB} ; \mathrm{r}=0.67\right)$ and lateral root length $\left(\mathrm{H}^{2}=0.38 \mathrm{CSIRO}\right.$, $0.36 \mathrm{NIAB} ; \mathrm{r}=0.65$ ) (Table 2). Leaf length and number had higher heritabilities than root phenotypes, but slightly lower repeatabilities (leaf length: $\mathrm{H}^{2}=0.84$ for CSIRO, 0.60 NIAB; $\mathrm{r}=0.58$; leaf number: $\left.\mathrm{H}^{2}=0.61 \mathrm{CSIRO} ; 0.67 \mathrm{NIAB} ; \mathrm{r}=0.42\right)$ (Table 2). Lateral and total root length are associated with good establishment in soil conditions (Section 4.5 below), and these can be combined with leaf length and number traits for selection for more vigorous root and shoot establishment in wheat. GrowScreen-PaGe is a suitable platform to increase line numbers for QTL identification based on their reasonable repeatabilities and scalability. We found heritability and repeatability values moderate to high compared to other studies. Moderate to high heritability for primary and lateral root length is reported 
in Arabidopsis [49], wheat [50,51], rice [52], and soybean [53]. Rebetzke and Richards (1999) reported that seedling leaf width was highly heritable and had a high genetic correlation with total leaf area in wheat during the vegetative stage [54]. Similarly, Gioia et al. (2016) reported high heritability for leaf number $\left(\mathrm{H}^{2}=0.95\right)$ and total root length $\left(\mathrm{H}^{2}=0.93\right)$ in rapeseed [37]. Traits with higher heritability are often controlled by fewer genes with larger effects [55]. The direct selection of traits with high heritability under strong genetic control enables genetic gain.

\subsection{CSIRO MAGIC Parents Grew Faster Than NIAB MAGIC Parents}

In general, the CSIRO MAGIC parents grew faster, produced larger root systems (mainly through greater total lateral root length), wider seminal root angle $\left(\mathrm{SRA}_{2 \mathrm{~cm}}\right)$ and more plant biomass compared to NIAB MAGIC parents (Figure 3, Figure S2). Differences between the founder parents may be explained by the different origin, genetic background, growing habit (spring/winter) and breeding targets of the populations (Figure 1, Table S1). Four of the CSIRO parents were bred in Australia, possibly contributing genes for traits conferring performance in low rainfed environments, such as rapid and long lateral root growth [56]. NIAB parents come from the UK and France, environments with higher rainfall than Australian wheat growing regions and with higher planting density practices, which may have selected against high total root length [11,12,57]. Additionally, narrow genetic background during breeding may have resulted in a smaller root system in NIAB parents compared to CSIRO $[12,58,59]$. Furthermore, two NIAB parents, Robigus and Soissons, carry the major dwarfing locus, 'reduced plant height' (Rht-B1), while six other parents carry the plant height reducing locus, Rht-D1 [11]. These dwarfing genes are gibberellic acid insensitive, decrease cell elongation and reduce leaf length and shoot biomass [60,61]. In the case of CSIRO MAGIC, two parents Chara7 and Baxter carry Rht-B1 while Yitpi and Westonia carry the Rht-D1 [10]. Studies have shown that dwarfing gene variation across MAGIC parents were associated with large reductions in coleoptile length that can impact the seedling establishment [62]. For example, reduction in coleoptile length was greater for Rht-D1 than Rht-B1. Furthermore, influence of embryo and seed size on early vigor and seedling traits were widely described in wheat $[63,64]$. Although our study did not focus on seed size, we have taken a great care for seedling uniformity by transplanting similar germinated seeds (length of first primary root) of MAGIC parents onto germination paper.

The significantly lower lateral root length in slow growing parents compared to fast growing parents (Figure $4 \mathrm{~A}-\mathrm{C}$ and Figure $4 \mathrm{E}-\mathrm{G}$ ) was a notable finding of this study. The exponential growth of lateral roots in fast growing parents Robigus and AC Barrie led to larger root systems compared to slow growing parents Rialto and G204 Xiaoyan54 (Figure 4D,H). Lateral roots are critical for exploring large volumes of soil for nutrients and water [65]. The role of contrasting RSA found in this study can be validated in future with experiments analyzing water and nutrient uptake by slow- and fast-growing parents, and progeny within the population

\subsection{Seminal Root Angle Was Not Correlated to Root System Depth}

Although wider seminal root angle $\left(\mathrm{SRA}_{5 \mathrm{~cm}}\right)$ was associated with longer total root length, we did not find a significant correlation with root system depth or width across both sets of MAGIC parents (Figure 6A,B). This supports more recent finding with the NIAB MAGIC parents, phenotyped over time in soil in 3D [66]. Rich et al. (2020) reported influence of the cultivation systems on formation of root angle in 19 diverse wheat cultivars [32]. They found no significant difference in root angle between first pairs of seminal roots grown in pouches, which was very similar to our findings. However, Rich et al. (2020) found significantly different root angles between second pairs of seminal roots when plants were grown in agar and soil [32]. In contrast, Manschadi et al., (2008); Nakamoto and Oyanagi, (1994); and Oyanagi (1994) reported that a narrow root angle promotes deeper root growth, also in wheat [67-69]. In those studies, the authors used diverse wheat cultivars which 
have wider genetic background compared to MAGIC parents analyzed in this study. They were grown in different cultivation systems and measured root angle differently compared to our study. These factors may have caused the contrasting results. Root angle is affected by the physical, chemical and biological conditions of soil and agar medium [70], and this makes it a challenging phenotype for selection in controlled conditions and translation to the field $[32,33,71,72]$. A new single plant selection pipeline developed for wheat uses phenotyping for root angle and marker selection for root biomass, opening new opportunities to optimize root angle and root depth for different field conditions [73].

\subsection{Biomass Allocation Patterns Vary in Between Fast and Slow Growing Parents}

The biomass of roots and shoots were positively correlated $\left(R^{2} \geq 0.74\right)$ in both sets of MAGIC parents (Figure 7D) suggesting that the root and shoot dry weight are linked and genetically shared the proportion of variance. Our results revealed notable differences in biomass allocation pattern between MAGIC parents expressed as root:shoot ratio (Table 3). Fast growing parents with larger root system (Robigus and AC Barrie) allocated a higher proportion of total biomass into roots, whereas the slow growing parents (Rialto and G204 Xiaoyan54) invested more resources to the shoots at 16 DAT (Table 3). As discussed above dwarfing genes may have reduced the coleoptile and leaf lengths, altering biomass allocation patterns between root and shoot $[10,13,15]$. Early allocation of more resources into roots covers the larger volume of ground, facilitates optimal intake of water and nutrient and helps rapid establishment. Our finding further suggest that greater belowground investment early can later result in larger shoot biomass. For example, the fast-growing parents Robigus and AC Barrie revealed both a larger root system and larger leaf length (up to 1.3 times, Tables S2 and S3) as compared to small root system parents Rialto and G204 Xiaoyan54. This may indicate a potential higher assimilation of canopy photosynthesis by large parents and supply of carbon to roots after depletion of seed reserves [74,75].

\subsection{Transfer of Results to Soil Conditions}

RSA is strongly influenced by abiotic and biotic conditions around roots [27,71]. We speculate from previous studies however that the rapid seminal and lateral root growth phenotypes will have relevance to field soil. For example, soil compaction [71], salinity [76], and certain rhizobacteria result in shorter and thicker primary roots, and more and longer lateral roots of wheat genotypes and the model brachypodium [77]. Soil moisture also strongly influences RSA, notably promoting the seminal system through lateral roots in drier conditions in wheat [78], brachypodium [79], and millet and sorghum [80]. Translation to the field ultimately requires validation at crop establishment [72] and yield [32] plant stages.

\section{Conclusions}

The founding parents of the NIAB and CSIRO MAGIC wheat populations have significant variation in RSA and shoot growth. Leaf length and number, and total and lateral root length, had highest variabilities and heritabilities. Progeny derived from the parents can be used to identify and map QTLs for these traits because of good repeatabilities in the updated, modular and scalable GrowScreen-PaGe. To maximize these promising targets for enhancing wheat establishment, progeny from both populations can be screened together to identify parents for new populations. Non-invasive phenotyping also revealed root and shoot allocation patterns: faster growing genotypes first allocated more biomass to roots than shoots, followed by faster lateral root growth and longer leaf length, than slower growing genotypes. Root:shoot allocation can be selected for dynamic establishment traits in future. 
Supplementary Materials: The following are available online at https:/ / www.mdpi.com/article/10 .3390 /agronomy 11122452 /s1, Figure S1. Workflow of the phenotyping system GrowScreen-PaGe. The wheat plants are grown in grey opaque containers. Figure S2. Variation for root angle measured between the two outmost seminal roots at a distance of $2 \mathrm{~cm}\left(\mathrm{SRA}_{2 \mathrm{~cm}}\right)$ at A) 2 days after transplanting (DAT), B) 9 DAT and C) 16 DAT. Table S1. List of MAGIC wheat founder parents used in this study, their origin, pedigree, and trait attributes. Table S2. Phenotyping variation for root and shoot traits of NIAB MAGIC wheat founder parents over time, mean values are shown. Table S3. Phenotyping variation for root and shoot traits of CSIRO MAGIC wheat founder parents over time, mean values are

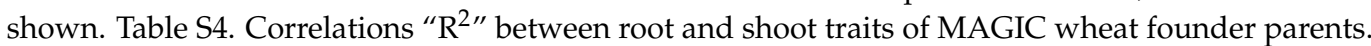
Root and shoot dry weight were measured at 16 days after transplanting. Table S5. Coefficient of variance "CV" across NIAB MAGIC wheat founder parents over time. Table S6. Coefficient of variance "CV" across CSIRO MAGIC wheat founder parents over time.

Author Contributions: K.A.N., C.F. and M.W. designed the study. J.L., A.G. and S.R.P. implemented the experiments and performed the data analysis. J.W., A.P. and K.H. updated the image-processing workflow and A.P., S.A. and A.G. designed the new growth container lids and modified the setup. S.R.P., K.A.N., C.F. and M.W. worked on interpretation of the data and wrote the manuscript. All authors read and approved the manuscript.

Funding: This project was supported by BASF SE and partly by third-party projects of the German Federal Ministry of Education and Research (MAZE Fz.031B0195G); and the German Federal Ministry of Food and Agriculture (MAGIC-Efficiency Fz.281B201916).

Data Availability Statement: The datasets generated are available for academic partners for noncommercial purposes upon request sent to the corresponding authors, provided that bilateral termsof-use agreements can be concluded.

Acknowledgments: We thank Carmen Müller, Bernd Kastenholz, and Ann-Katrin Kleinert for their assistance during the experiments, and Sebastian Steinemann for his help in setting up the experimental design. Furthermore, we thank Natalie Wuyts and Jose Correa for support in data (R program) analysis. Michelle Watt holds the Adrienne Clarke Professorial Chair of Botany, which is supported through the University of Melbourne Botany Foundation. We are grateful for the provision of MAGIC parents by NIAB and CSIRO.

Conflicts of Interest: The authors declare no conflict of interest.

\section{References}

1. Shewry, P.R.; Hey, S.J. The contribution of wheat to human diet and health. Food Energy Secur. 2015, 4, 178-202. [CrossRef]

2. Shewry, P.R. Wheat. J. Exp. Bot. 2009, 60, 1537-1553. [CrossRef] [PubMed]

3. Dubcovsky, J.; Dvorak, J. Genome plasticity a key factor in the success of polyploid wheat under domestication. Science 2007, 316, 1862-1866. [CrossRef]

4. Huang, X.; Börner, A.; Röder, M.; Ganal, M. Assessing genetic diversity of wheat (Triticum aestivum L.) germplasm using microsatellite markers. Theor. Appl. Genet. 2002, 105, 699-707. [CrossRef]

5. Matsuoka, Y. Evolution of polyploid Triticum wheats under cultivation: The role of domestication, natural hybridization and allopolyploid speciation in their diversification. Plant Cell Physiol. 2011, 52, 750-764. [CrossRef] [PubMed]

6. Appels, R.; Eversole, K.; Feuille, C.; Keller, B.; Rogers, J.; Stein, N.; The International Wheat Genome Sequencing Consortium (IWGSC). Shifting the limits in wheat research and breeding using a fully annotated reference genome. Science 2018, 361, 1110-1126.

7. Cavanagh, C.; Morell, M.; Mackay, I.; Powell, W. From mutations to MAGIC: Resources for gene discovery, validation and delivery in crop plants. Curr. Opin. Plant Biol. 2008, 11, 215-221. [CrossRef]

8. Huang, X.; Paulo, M.J.; Boer, M.; Effgen, S.; Keizer, P.; Koornneef, M.; van Eeuwijk, F.A. Analysis of natural allelic variation in Arabidopsis using a multiparent recombinant inbred line population. PNAS 2011, 108, 4488-4493. [CrossRef]

9. Kover, P.X.; Valdar, W.; Trakalo, J.; Scarcelli, N.; Ehrenreich, I.M.; Purugganan, M.D.; Durrant, C.; Mott, R. A multiparent advanced generation inter-cross to fine-map quantitative traits in Arabidopsis thaliana. PLoS Genet. 2009, 5, e1000551. [CrossRef]

10. Huang, B.E.; George, A.W.; Forrest, K.L.; Kilian, A.; Hayden, M.J.; Morell, M.K.; Cavanagh, C.R. A multiparent advanced generation inter-cross population for genetic analysis in wheat. Plant Biotechnol. J. 2012, 10, 826-839. [CrossRef] [PubMed]

11. Mackay, I.J.; Bansept-Basler, P.; Barber, T.; Bentley, A.R.; Cockram, J.; Gosman, N.; Greenland, A.J.; Horsnell, R.; Howells, R.; O'Sullivan, D.M.; et al. An eight-parent multiparent advanced generation inter-cross population for winter-sown wheat: Creation, properties, and validation. G3: Genes Genom. Genet. 2011, 4, 1603-1610. [CrossRef] 
12. Fradgley, N.; Bentley, A.R.; Gardner, K.A.; Howell, P.; Mackay, I.J.; Scott, M.; Mott, R.; Cockram, J. A 16 Founder Wheat MAGIC Population for QTL Mapping. In Proceedings of the Plant and Animal Genome XXVI Conference, San Diego, CA, USA, 13-17 January 2018.

13. Huang, B.E.; Verbyla, K.L.; Verbyla, A.P.; Raghavan, C.; Singh, V.K.; Gaur, P.; Leung, H.; Varshney, R.K.; Cavanagh, C.R. MAGIC populations in crops: Current status and future prospects. Theor. Appl. Genet. 2015, 128, 999-1017. [CrossRef] [PubMed]

14. Stadlmeier, M.; Hartl, L.; Mohler, V. Usefulness of a Multiparent Advanced Generation Intercross Population with a greatly reduced mating design for genetic studies in winter wheat. Front. Plant Sci. 2018, 9, 1825. [CrossRef]

15. Delhaize, E.; Rathjen, T.M.; Cavanagh, C.R. The genetics of rhizosheath size in a multiparent mapping population of wheat. J. Exp. Bot. 2015, 66, 4527-4536. [CrossRef] [PubMed]

16. Rebetzke, G.J.; Verbyla, A.P.; Verbyla, K.L.; Morell, M.K.; Cavanagh, C.R. Use of a large multiparent wheat mapping population in genomic dissection of coleoptile and seedling growth. Plant Biotechnol. J. 2014, 12, 219-230. [CrossRef] [PubMed]

17. Barrero, J.M.; Cavanagh, C.; Verbyla, K.L.; Tibbits, J.F.; Verbyla, A.P.; Huang, B.E.; Rosewarne, G.M.; Stephen, S.; Wang, P.; Whan, A.; et al. Transcriptomic analysis of wheat near-isogenic lines identifies PM19-A1 and A2 as candidates for a major dormancy QTL. Genome Biol. 2015, 16, 1-18. [CrossRef]

18. Boden, S.A.; Cavanagh, C.; Cullis, B.R.; Ramm, K.; Greenwood, J.; Finnegan, E.J.; Trevaskis, B.; Swain, S.M. Ppd-1 is a key regulator of inflorescence architecture and paired spikelet development in wheat. Nat. Plants 2015, 1, 1-6. [CrossRef]

19. Richards, R.A.; Cavanagh, C.R.; Riffkin, P. Selection for erect canopy architecture can increase yield and biomass of spring wheat. Field Crop. Res. 2019, 244, 107649. [CrossRef]

20. Camargo, A.V.; Mackay, I.; Mott, R.; Han, J.; Doonan, J.H.; Askew, K.; Corke, F.; Williams, K.; Bentley, A.R. Functional mapping of quantitative trait loci (QTLs) associated with plant performance in a wheat magic mapping population. Front. Plant Sci. 2018, 9, 887. [CrossRef] [PubMed]

21. Riaz, A.; KockAppelgren, P.; Hehir, J.G.; Kang, J.; Meade, F.; Cockram, J.; Milbourne, D.; Spink, J.; Mullins, E.; Byrne, S. Genetic analysis using a multi-parent wheat population identifies novel sources of Septoria tritici blotch resistance. Genes 2020, $11,887$. [CrossRef] [PubMed]

22. Lin, M.; Corsi, B.; Ficke, A.; Tan, K.C.; Cockram, J.; Lillemo, M. Genetic mapping using a wheat multi-founder population reveals a locus on chromosome $2 \mathrm{~A}$ controlling resistance to both leaf and glume blotch caused by the necrotrophic fungal pathogen Parastagonospora nodorum. Theor. Appl. Genet. 2020, 133, 785-808. [CrossRef]

23. Gregory, P.J.; Eastham, J. Growth of shoots and roots, and interception of radiation by wheat and lupin crops on a shallow, duplex soil in response to time of sowing. Aust. J. Agric. Res. 1996, 47, 427-447. [CrossRef]

24. Thorup-Kristensen, K.; Cortasa, M.S.; Loges, R. Winter wheat roots grow twice as deep as spring wheat roots, is this important for $\mathrm{N}$ uptake and $\mathrm{N}$ leaching losses? Plant Soil 2009, 322, 101-114. [CrossRef]

25. Tracy, S.R.; Nagel, K.A.; Postma, J.A.; Fassbender, H.; Wasson, A.; Watt, M. Crop improvement from phenotyping roots: Highlights reveal expanding opportunities. Trends Plant Sci. 2020, 25, 105-118. [CrossRef] [PubMed]

26. Lynch, J. Root architecture and plant productivity. Plant Physiol. 1995, 109, 7. [CrossRef]

27. Rich, S.M.; Watt, M. Soil conditions and cereal root system architecture: Review and considerations for linking Darwin and Weaver. J. Exp. Bot. 2013, 64, 1193-1208. [CrossRef] [PubMed]

28. Severini, A.D.; Wasson, A.P.; Evans, J.R.; Richards, R.A.; Watt, M. Root phenotypes at maturity in diverse wheat and triticale genotypes grown in three field experiments: Relationships to shoot selection, biomass, grain yield, flowering time, and environment. Field Crop. Res. 2020, 255, 107870. [CrossRef]

29. Asif, M.; Kamran, A. Plant breeding for water-limited environments. Crop. Sci. 2011, 51, 2911-2912. [CrossRef]

30. Carvalho, P.; Azam-Ali, S.; Foulkes, M.J. Quantifying relationships between rooting traits and water uptake under drought in Mediterranean barley and durum wheat. J. Integr. Plant Biol. 2014, 56, 455-469. [CrossRef] [PubMed]

31. King, J.; Gay, A.; Sylvester-Bradley, R.; Bingham, I.; Foulkes, J.; Gregory, P.; Robinson, D. Modelling cereal root systems for water and nitrogen capture: Towards an economic optimum. Ann. Bot. 2003, 91, 383-390. [CrossRef]

32. Rich, S.M.; Christopher, J.; Richards, R.; Watt, M. Root phenotypes of young wheat plants grown in controlled environments show inconsistent correlation with mature root traits in the field. J. Exp. Bot. 2020, 71, 4751-4762. [CrossRef]

33. Watt, M.; Magee, L.J.; McCully, M.E. Types, structure and potential for axial water flow in the deepest roots of field-grown cereals. New Phytol. 2008, 178, 135-146. [CrossRef]

34. Xie, Q.; Fernando, K.M.; Mayes, S.; Sparkes, D.L. Identifying seedling root architectural traits associated with yield and yield components in wheat. Ann. Bot. 2017, 119, 1115-1129. [CrossRef]

35. Ahmed, M.A.; Zarebanadkouki, M.; Kaestner, A.; Carminati, A. Measurements of water uptake of maize roots: The key function of lateral roots. Plant Soil 2016, 398, 59-77. [CrossRef]

36. Varney, G.; Canny, M. Rates of water uptake into the mature root system of maize plants. New Phytol. 1993, 123, 775-786. [CrossRef]

37. Gioia, T.; Galinski, A.; Lenz, H.; Müller, C.; Lentz, J.; Muller, C.; Lentz, J.; Heinz, K.; Briese, C.; Putz, A.; et al. GrowScreen-PaGe, a non-invasive, high-throughput phenotyping system based on germination paper to quantify crop phenotypic diversity and plasticity of root traits under varying nutrient supply. Funct. Plant Biol. 2016, 44, 76-93. [CrossRef] 
38. Richards, R.A.; Rebetzke, G.J.; Watt, M.; Condon, A.T.; Spielmeyer, W.; Dolferus, R. Breeding for improved water productivity in temperate cereals: Phenotyping, quantitative trait loci, markers and the selection environment. Funct. Plant Biol. 2010, 37, 85-97. [CrossRef]

39. Wissuwa, M.; Kretzschmar, T.; Rose, T.J. From promise to application: Root traits for enhanced nutrient capture in rice breeding. J. Exp. Bot. 2016, 67, 3605-3615. [CrossRef] [PubMed]

40. Watt, M.; Fiorani, F.; Usadel, B.; Rascher, U.; Muller, O.; Schurr, U. Phenotyping: New Windows into the Plant for Breeders. Annu. Rev. Plant Biol. 2020, 71, 689-712. [CrossRef] [PubMed]

41. Wasson, A.P.; Nagel, K.A.; Tracy, S.; Watt, M. Beyond Digging: Noninvasive Root and Rhizosphere Phenotyping. Trends Plant Sci. 2020, 25, 119-120. [CrossRef]

42. Hoagland, D.R.; Arnon, D.I. The water-culture method for growing plants without soil. In Circular, 2nd ed.; California Agricultural Experiment Station: St. Thomas, VI, USA, 1950; Volume 347, pp. 1-32.

43. Falconer, D.; Mackay, T. Introduction to Quantitative Genetics; Harlow, Ed.; Longmans Green: Essex, UK, 1996.

44. Holland, J.B.; Nyquist, W.E.; Cervantes-Martínez, C.T. Estimating and interpreting heritability for plant breeding: An update. Plant Breed. 2003, 22, 9-112.

45. Stoffel, M.A.; Nakagawa, S.; Schielzeth, H. rptR: Repeatability estimation and variance decomposition by generalized linear mixed-effects models. Methods Ecol. Evol. 2017, 11, 1639-1644. [CrossRef]

46. RCore, Team. R: A Language and Environment for Statistical Computing; R Foundation for Statistical Computing: Vienna, Austria, 2016; Available online: https:/ / www.r-project.org/ (accessed on 14 February 2019).

47. Pang, J.; Palta, J.A.; Rebetzke, G.J.; Milroy, S.P. Wheat genotypes with high early vigour accumulate more nitrogen and have higher photosynthetic nitrogen use efficiency during early growth. Funct. Plant Biol. 2013, 41, 215-222. [CrossRef]

48. Watt, M.; Kirkegaard, J.A.; Rebetzke, G.J. A wheat genotype developed for rapid leaf growth copes well with the physical and biological constraints of unploughed soil. Funct. Plant Biol. 2005, 32, 695-706. [CrossRef]

49. Richard, O.; Pineau, C.; Loubet, S.; Chalies, C.; Vile, D.; Marquès, L.; Berthomieu, P. Diversity analysis of the response to Zn within the Arabidopsis thaliana species revealed a low contribution of $\mathrm{Zn}$ translocation to $\mathrm{Zn}$ tolerance and a new role for $\mathrm{Zn}$ in lateral root development. Plant Cell Environ. 2011, 34, 1065-1078. [CrossRef]

50. Dhanda, S.; Sethi, G.; Behl, R. Indices of drought tolerance in wheat genotypes at early stages of plant growth. J. Agron. Crop. Sci. 2004, 190, 6-12. [CrossRef]

51. Laperche, A.; Devienne-Barret, F.; Maury, O.; Le Gouis, J.; Ney, B. A simplified conceptual model of carbon/nitrogen functioning for QTL analysis of winter wheat adaptation to nitrogen deficiency. Theor. Appl. Genet. 2006, 113, 1131-1146. [CrossRef] [PubMed]

52. MacMillan, K.; Emrich, K.; Piepho, H.P.; Mullins, C.; Price, A. Assessing the importance of genotype x environment interaction for root traits in rice using a mapping population. I: A soil-filled box screen. Theor. Appl. Genet. 2006, 113, 977-986. [CrossRef]

53. Ao, J.; Fu, J.; Tian, J.; Yan, X.; Liao, H. Genetic variability for root morph-architecture traits and root growth dynamics as related to phosphorus efficiency in soybean. Funct. Plant Biol. 2010, 37, 304-312. [CrossRef]

54. Rebetzke, G.J.; Richards, R.A. Genetic improvement of early vigour in wheat. Aust. J. Agric. Res. 1999, 50, 291-301. [CrossRef]

55. Tsegaye, D.; Dessalegn, T.; Dessalegn, Y.; Share, G. Genetic variability, correlation and path analysis in durum wheat germplasm (Triticum durum Desf). Agric. Res. Rev. 2012, 1, 107-112.

56. Palta, J.A.; Watt, M. Vigorous crop root systems: Form and function for improving the capture of water and nutrients. In Applications for Genetic Improvement and Agronomy; Sadras, V., Calderini, D., Eds.; Elsevier: Amsterdam, The Netherlands, 2009; pp. 309-325.

57. Fradgley, N.; Evans, G.; Biernaskie, J.M.; Cockram, J.S.; Marr, E.C.; Oliver, A.G.; Ober, E.; Jones, H. Effects of breeding history and crop management on the root architecture of wheat. Plant Soil 2020, 452, 587-600. [CrossRef]

58. Camargo, A.V.; Mott, R.; Gardner, K.A.; Mackay, I.J.; Corke, F.; Doonan, J.H.; Kim, J.T.; Bentley, A.R. Determining phenological patterns associated with the onset of senescence in a wheat MAGIC mapping population. Front. Plant Sci. 2016, 7, 1540. [CrossRef]

59. Subbiah, B.; Katyal, J.; Narasimham, R.; Dakshinamurti, C. Preliminary investigations on root distribution of high yielding wheat varieties. Int. J. Appl. Radiat. Isotopes 1968, 19, 385-390. [CrossRef]

60. Botwright, T.; Rebetzke, G.; Condon, A.; Richards, R. Influence of the gibberellin-sensitive Rht8 semi-dwarf gene on leaf anatomy and seedling vigour in wheat (Triticum aestivum L.). Ann. Bot. 2005, 95, 631-639. [CrossRef]

61. Ellis, M.H.; Rebetzke, G.J.; Chandler, P.; Bonnett, D.; Spielmeyer, W.; Richards, R.A. The effect of different height reducing genes on the early growth of wheat. Funct. Plant Biol. 2004, 31, 583-589. [CrossRef] [PubMed]

62. Rebetzke, G.J.; Ellis, M.H.; Bonnett, D.G.; Richards, R.A. Molecular mapping of genes for coleoptile growth in bread wheat (Triticum aestivum L.). Theor. Appl. Genet. 2007, 114, 1173-1183. [CrossRef] [PubMed]

63. Maydup, M.L.; Graciano, C.; Guiamet, J.J.; Tambussi, E.A. Analysis of early vigour in twenty modern cultivars of bread wheat (Triticum aestivum L.). Crop. Pasture Sci. 2012, 63, 987-996. [CrossRef]

64. Moore, C.; Rebetzke, G. Genomic regions for embryo size and early vigour in multiple wheat (Triticum aestivum L.) populations. Agronomy 2015, 5, 152-179. [CrossRef]

65. Von Wangenheim, D.; Banda, J.; Schmitz, A.; Boland, J.; Bishopp, A.; Maizel, A.; Stelzer, E.H.K.; Bennett, M. Early developmental plasticity of lateral roots in response to asymmetric water availability. Nat. Plants 2020, 6, 73-77. [CrossRef] [PubMed] 
66. Pflugfelder, D.; Kochs, J.; Koller, R.; Jahnke, S.; Mohl, C.; Pariyar, S.R.; Fassbender, H.; Nagel, K.A.; Watt, M.; van Dusschoten, D. The root system architecture of wheat establishing in soil is associated with varying elongation rates of seminal roots. J. Exp. Bot.. (under review).

67. Manschadi, A.M.; Hammer, G.L.; Christopher, J.T.; Devoil, P. Genotypic variation in seedling root architectural traits and implications for drought adaptation in wheat (Triticum aestivum L.). Plant Soil 2008, 303, 115-129. [CrossRef]

68. Nakamoto, T.; Oyanagi, A. The direction of growth of seminal roots of Triticum aestivum L. and experimental modification thereof. Ann. Bot. 1994, 73, 363-367. [CrossRef]

69. Oyanagi, A. Gravitropic response growth angle and vertical distribution of roots of wheat (Triticum aestivum L.). Plant Soil 1994, 165, 323-326. [CrossRef]

70. Watt, M.; Silk, W.K.; Passioura, J.B. Rates of root and organism growth, soil conditions, and temporal and spatial development of the rhizosphere. Ann. Bot. 2006, 97, 839-855. [CrossRef] [PubMed]

71. Watt, M.; McCully, M.E.; Kirkegaard, J.A. Soil strength and rate of root elongation alter the accumulation of Pseudomonas spp. and other bacteria in the rhizosphere of wheat. Funct. Plant Biol. 2003, 30, 483-491. [CrossRef]

72. Watt, M.; Moosavi, S.; Cunningham, S.C.; Kirkegaard, J.A.; Rebetzke, G.J.; Richards, R.A. A rapid, controlled-environment seedling root screen for wheat correlates well with rooting depths at vegetative, but not reproductive, stages at two field sites. Ann. Bot. 2013, 112, 447-455. [CrossRef]

73. Rambla, C.; Van Der Meer, S.; Voss-Fels, K.P.; Makhoul, M.; Obermeier, C.; Snowdon, R.; Ober, E.S.; Watt, M.; Alahmad, S.; Hickley, L.T. A Toolkit to Rapidly Modify Root Systems Through Single Plant Selection. Ann. Bot.. (accepted; in press).

74. Palta, J.; Gregory, P. Drought affects the fluxes of carbon to roots and soil in 13C pulse-labelled plants of wheat. Soil Biol. Biochem. 1997, 29, 1395-1403. [CrossRef]

75. Palta, J.A.; Chen, X.; Milroy, S.P.; Rebetzke, G.J.; Dreccer, M.F.; Watt, M. Large root systems: Are they useful in adapting wheat to dry environments? Funct. Plant Biol. 2011, 38, 347-354. [CrossRef]

76. Rahnama, A.; Munns, R.; Poustini, K.; Watt, M. A screening method to identify genetic variation in root growth response to a salinity gradient. J. Exp. Bot. 2011, 62, 69-77. [CrossRef] [PubMed]

77. Schillaci, M.; Arsova, B.; Walker, R.; Smith, P.M.; Nagel, K.A.; Roessner, U.; Watt, M. Time-resolution of the shoot and root growth of the model cereal Brachypodium in response to inoculation with Azospirillum bacteria at low phosphorus and temperature. Plant Growth Regul. 2021, 93, 149-162. [CrossRef]

78. Volkmar, K.M. Water stressed nodal roots of wheat: Effects on leaf growth. Funct. Plant Biol. 1997, 24, 49-56. [CrossRef]

79. Chochois, V.; Vogel, J.P.; Rebetzke, G.J.; Watt, M. Variation in adult plant phenotypes and partitioning among seed and stem-borne roots across Brachypodium distachyon accessions to exploit in breeding cereals for well-watered and drought environments. Plant Physiol. 2015, 168, 953-967. [CrossRef] [PubMed]

80. Rostamza, M.; Richards, R.A.; Watt, M. Response of millet and sorghum to a varying water supply around the primary and nodal roots. Ann. Bot. 2013, 112, 439-446. [CrossRef] [PubMed] 